\title{
Konsep-Konsep Tasawuf dan Relevansinya dalam Kehidupan
}

\author{
Arrasyid Arrasyid \\ Universitas Islam Negeri Sunan Kalijaga Yogyakarta \\ e-mail: arrasyid350@gmail.com
}

\begin{abstract}
The rapid development of the times has positive and negative impacts on life. Moral and spiritual degradation is one of the negative impacts that emerge like humans living without a clear purpose. Resulting in high crime both drug abuse, juvenile delinquency and so on. These problems make humans a cause as well as those responsible for solving them. Meanwhile conceptually the problem is closely related to personality problems or in Islam is called morals. The purpose of this study is to describe and review the concepts of Sufism and its relevance in everyday life. This research is a Library Research Because of that the data source is in the form of library materials such as books, journals and scientific articles. In accordance with the type, the data collection in this study uses library research methods which are analysis using the method of description and data analysis. The results of research this is maqamat and ahwal shown are by Abu Nasr al-Sarraj, the author of AlLuma' Reference Complete Science of Sufism, which maqamat that there are seven, namely: repentance, wara, ascetic, fakir, patient, trust, and pleasure. The ahwal are muraqabah, mahabbah, khauf, raja', syauq,' uns, tuma'ninah, musyahadah, and sure. The relevance of the concepts of Sufism to present life is that these concepts will become a guideline for achieving a true approach to God.
\end{abstract}

Keyword: The Concept, Sufism, Its Relevance in Life.

\begin{abstract}
Abstrak
Pesatnya perkembangan zaman memiliki dampak positif dan negatif pada kehidupan. Kerusakan moral dan spiritual adalah salah satu dampak negatif yang muncul seperti manusia yang hidup tanpa tujuan yang jelas. Menghasilkan kejahatan tinggi baik penyalahgunaan narkoba, kenakalan remaja dan sebagainya. Masalah-masalah ini membuat manusia sebagai penyebab serta mereka yang bertanggung jawab untuk menyelesaikannya. Sementara itu secara konseptual masalah terkait erat dengan masalah kepribadian atau dalam Islam disebut akhlak. Tujuan dari penelitian ini adalah untuk menggambarkan dan meninjau konsep tasawuf dan relevansinya dalam kehidupan sehari-hari. Penelitian ini adalah Penelitian Perpustakaan Karena itu sumber datanya berupa bahan pustaka seperti buku, jurnal dan artikel ilmiah. Sesuai dengan jenisnya, pengumpulan data dalam penelitian ini menggunakan metode penelitian kepustakaan yang dianalisis menggunakan metode deskripsi dan analisis data. Hacyl penelitian ini adalah maqamat dan ahwal yang diperlihatkan oleh Abu Nasr alSarraj, penulis Al-Luma 'Referensi Lengkap Ilmu Sufisme, yang maqamat itu ada tujuh, yaitu: pertobatan, wara, pertapa, fakir, pasien, kepercayaan, dan kesenangan. Ahwal adalah muraqabah, mahabbah, khauf, raja ', syauq,' uns, tuma'ninah, musyahadah, dan tentu saja. Relevansi konsep Sufisme dengan kehidupan sekarang adalah bahwa konsep-konsep ini akan menjadi pedoman untuk mencapai pendekatan yang benar kepada Tuhan.
\end{abstract}

Kata kunci: Konsep, Sufisme, Relevansinya dalam Kehidupan. 


\section{Pendahuluan}

Tasawuf adalah jalan atau cara untuk mendekatkan diri kepada Allah SWT. dengan cara mempraktekan konsepkonsep yang ada dalam tasawuf. Konsepkonsep yang ada dalam tasawuf mengarahkan manusia atau sufi untuk berada sedekat mungkin dengan Allah SWT. Tasawuf juga merupakan rangkaian eksperimen jiwa dalam menempuh jalan penyucian dan penempaan rohani yang dituntun oleh kerinduan kepada Allah. Dalam tasawuf ada maqamat dan ahwal. Maqamat adalah konsep dalam tasawuf yang menunjukkan kedudukan spiritual seorang sufi di mata Allah. Maqamat ini sifatnya tentu sangat subjketif, Karena berdasarkan pengalaman spiritual masing-masing sufi. Begitupun dengan ahwal umumnya buku-buku tasawuf memiliki subjektifitas sendiri dalam merumuskan kondisi spiritual atau ahwal.

Baik maqamat maupun ahwal adalah konsep tasawuf yang bisa dicapai dan dirasakan oleh semua orang, jika ia step by step mengikuti alur maqamat yang dihadirkan dalam kajian tasawuf. Setelah manusia bisa melewati step by step maqamat tasawuf maka Allah akan memberi ia kondisi-kondisi spiritual tentang pengalaman dengan Tuhan. Selain itu, konsep-konsep tasawuf ini, atau tepatnya maqamat dan ahwal ini, tentu bukanlah hal yang baru dalam dunia tasawuf. Sejak tasawuf ada maka konsep inipun tentunya hadir. Melihat pada masa sekarang apakah masih relevan konsep tersebut dengan zaman sekarang sehingga bisa dipraktekan oleh siapapun yang ingin merasakan kedekatan dan pengalaman spiritual dengan Tuhan. Maka, oleh sebab itu, penting kiranya untuk mengetahui bagaimana maqamat dan ahwal dalam tasawuf dan relevannsinya dengan kehidupan sekarang ini.

Penelitian ini adalah penelitian kepustakaan (librabry research) penelitian yang dilaksanakan dengan literatur (kepustakaan) maka sumber-sumber yang penulis gunakan adalah buku-buku yang memuat tentang tasawuf, catatan maupun laporan penelitian terdahulu. Dengan menggunakan metode deskripsi, interpretasi dan analisis. yakni metode dalam bentuk deskripsi agar penulis mampu memahami dan memberikan gambaran yang jelas mengenai permasalahan yang terkait dengan penelitian ini. Dan metode analisis digunakan agar penulisan ini lebih sistematis pada permasalahan yang akan dibahas dalam penelitian ini. Adapun sumber data penelitian ini adalah sumber data primer dan sember data sekunder. Adapun sumber data primernya bukubuku yang memuat tentang tasawuf. 
Seperti antara lain; kitab Al-Luma': Rujukan Lengkap Ilmu Tasawuf. Adapun sumber data sekundernya adalah karyakarya lain yang berkaitan dengan penelitian ini.

\section{Maqamat Tasawuf}

Maqamat adalah bentuk jamak dari kata maqam. Secara etimologi berarti tempat berdiri, stasiun, tempat, lokasi, posisi, atau tingkatan. Adapun secara terminologi maqamat diartikan sebagai tempat atau martabat seorang hamba di hadapan Allah pada saat ia berdiri menghadap kepada-Nya. Ia merupakan proses training, melatih diri dalam hidup keruhanian (riyadhah), latihan memerangi hawa nafsu (mujahadah), dan melepaskan kegiatan dunia untuk semata-mata berbakti kepada Allah. ${ }^{1}$ Adapun menurut al-Hujwiri (w. $465 \quad \mathrm{H} \quad / 1072 \quad \mathrm{M})$, maqamatmerupakan keberadaan seseorang di jalan Allah. Lalu, ia memenuhi kewajiban-kewajiban yang berkaitan dengan maqam itu serta menjaganya hingga ia mencapai kesempurnaannya, sejauh berada dalam kekuatan manusia. ${ }^{2}$ Sedangkan menurut Imam al-Qusyairy alNaisabury menjelaskan maqam adalah tahapan adab (etika) seorang hamba

\footnotetext{
${ }^{1}$ Moenir Nahrowi Tohir, Menjelajahi Eksistensi Tasawuf: Meniti Jalan Menuju Tuhan..., hlm. 93.

2Media Zainul Bahri, Tasawuf Mendamaikan Dunia, (Jakarta: Gapprint, 2010), hlm. 84-85.
}

dalam wushul kepada-Nya dengan macam upaya, di-wujud-kan dengan suatu tujuan pencarian dan ukuran tugas. Masingmasing berada dalam tahapannya sendiri ketika dalam kondisi tersebut, serta tingkah laku riyadhah menuju kepadaNya. ${ }^{3}$ Berdasarkan penjelasan di atas sederhananya maqamat adalah kedudukan atau posisi seseorang hamba di hadapan Allah yang ia istiqamah pada kedudukan tersebut dan berusaha untuk meningkatkannya hingga mencapai derajat puncak.

Adapun maqamat tersebut yaitu:

1. Taubat

$$
\text { Maqamat pertama dalam }
$$
tasawuf adalah taubat, "pertaubatan".4 Secara etimologi taubat berasal dari kata taba, yatubu, taubatan artinya kembali. ${ }^{5}$ Taubat berarti berpaling dari dosa, untuk menghilangkan segala keprihatinan duniawi. ${ }^{6}$ Taubat juga berarti kembali dari sesuatu yang dicela oleh syara menuju sesuatu yang dipuji oleh-Nya.7 Menurut Qamar Kailani dalam bukunya $F i$ al-

3Imam al-Qusyairy an-Naisabury, Risalah Qusyairyah: Induk Ilmu Tasawuf,terj. Mohammad Luqman Hakiem, (Surabaya: Risalah Gusti, 2014), hlm. 23.

${ }^{4}$ Annemarie Schimmel, Mystical Dimensions of Islam, (America: The Universit y of North Carolina Press, 1975), hlm. 109.

${ }^{5}$ Abuddin Nata, Akhlak Tasawuf dan Karakter Mulia, (Jakarta: Rajawali Oers, 2013), hlm. 171.

${ }^{6}$ Annemarie Schimmel, Mystical Dimensions of Islam..., hlm. 23.

7Bachrun Rif'I dan Hasan Mud'is, Filsafat Tasawuf, (Bandung: CV. Pustaka Setia, 2010), hlm. 202. 
Tashawwuf al-Islami, yang dikutip dari buku Ilmu Tasawuf karangan $\mathrm{M}$. Solihin dan Rosihon Anwar taubat adalah rasa penyesalan yang sungguhsungguh dalam hati disertai permohonan ampun serta meninggalkan segala perbuatan yang menimbulkan dosa. ${ }^{8}$ Adapun menurut Fethullah Gulen taubat adalah bertawajuh kepada Allah dengan penuh penyesalan dan rasa perih di dalam hati seraya mengakui semua kesalahan, meratap dalam penyesalan, dan tekad untuk meninggalkan kesalahan yang lalu. ${ }^{9}$ Berdasarkan penjelasan di atas sederhananya taubat adalah menyesali kesalahan dengan meminta ampun kepada Allah dengan berkomitmen tidak akan mengulanginya lagi.

2. Wara'

Secara harfiah wara' artinya saleh, menjauhkan diri dari perbuatan dosa. Kata ini selanjutnya mengandung arti menjauhi hal-hal yang tidak baik. Al-Ustaz al-Imam r.a berkata, "yang dimaksud wara' adalah meninggalkan hal-hal yang syubhat." Adapun Ibrahim bin Adham juga

${ }^{8}$ M. Solihin, dan Rosihon Anwar, Ilmu Tasawuf, (Bandung: CV Pustaka Setia, 2008), hlm. 78.

${ }^{9}$ Muhammad Fethullah Gulen, Tasawuf Untuk Kita Semua: Menapaki Bukit-bukit Zamrud Kalbu Melalui Istilah-istilah dalam Praktik Sufisme, terj. Fuad Syaifudin Nur, (Jakarta: Republika, 2013), hlm. 25. memberikan komentarnya yang

dimaksud dengan wara', yaitu meninggalkan hal-hal yang syubhat dan yang tidak pasti (tidak dikehendaki), yakni meninggalkan hal-hal yang tidak berfaedah."10 Sedangkan menurut Fethullah Gulen wara' adalah menghindari segala hal yang tidak pantas, tidak sesuai, dan tidak perlu, serta berhati-hati terhadap hal-hal yang diharamkan dan dilarang. Wara juga berarti menghindari segala bentuk syubhat karena takut terperosok dalam hal yang haram. Semua ini sesuai dengan sebuah kaidah yang berbunyi, "Tinggalkanlah yang meragukanmu menuju yang tidak meragukanmu."11

3. Zuhud

Secara etimologi zuhud berarti tidak ingin kepada sesuatu yang bersifat keduniawian. ${ }^{12}$ Adapun secara terminologi, menurut Ibnu Qayyim alJauziyah zuhud adalah perjalanan hati dari kampung dunia dan menempatkannya di akhirat.13Sebuah

${ }^{10}$ Abul Qasim Abdul Karim Hawazin alQusyairi an-Naisaburi, Risalah Qusyairiyah: Sumber Kajian Ilmu Tasawuf, terj. Umar Faruq, (Jakarta: Pustaka Amani, 2007), hlm. 146.

${ }^{11}$ Muhammad Fethullah Gulen, Tasawuf Untuk Kita Semua: Menapaki Bukit-bukit Zamrud Kalbu Melalui Istilah-istilah dalam Praktik Sufisme...,hlm. 107.

${ }^{12}$ Mahmud Yunus, Kamus Arab, (Jakarta:Hidakarya Agung, 1990), hlm. 362.

${ }^{13}$ Ibnu Qayyim al-Jauziyah,Madarijus Salikin: Pendakian Menuju Allah Penjabaran Konkrit "Iyyaka Na'budu 
perjalanan tentunya membutuhkan bekal agar bertenaga sehingga perjalanan dapat dinikmati. Bekal inilah sebagai modal manusia untuk bisa bertahan dalam hidup ini sehingga bisa menjalani hidup dengan tenang dan bahagia sehingga fokus mencapai akhirat.Adapun Ibnu Taimiyyah berpendapat bahwa zuhud itu berarti meninggalkan apa-apa yang tidak bermanfaat untuk kepentingan akhirat. ${ }^{14}$ Sedangkan HAMKA sebagai tokoh Tasawuf Modern berpendapat bahwa Zuhud akan dunia itu adalah sudi miskin, sudi kaya, sudi tidak beruang sepeser juga, sudi jadi miliuner, tetapi harta itu tidak menjadi sebab buat dia melupakan Tuhan, atau lalai dari kewajiban. ${ }^{15}$ Dengan demikian dapat dipahami, bahwa zuhud adalah hati dan pikiran tetap tenang bersama dunia sehingga tidak menganggu hubungan dengan Allah. Sederhananya zuhud yaitu kedekatan dengan dunia tidak menganggu kedekatan dengan Allah.

4. Fakir

Secara harfiah fakir biasanya diartikan sebagai orang yang berhajat,

Wa Iyyaka Nasta'in,"terj. Kathur Suhardi, (Jakarta: Pustaka al-Kautsar, 2017), hlm. 195.

${ }^{14}$ Bachrun Rif'I dan Hasan Mud'is, Filsafat Tasawuf..., hlm. 207. butuh atau orang miskin. Sedangkan dalam pandangan sufi fakir adalah tidak meminta lebih dari apa yang telah ada pada diri kita. Tidak meminta rezeki kecuali hanya untuk dapat menjalankan kewajibankewajiban. Tidak meminta sungguhpun tak ada pada diri kita, kalau diberi diterima. Tidak meminta tetapi tidak menolak.16 Fethullah Gulen mengartikan bahwa fakir adalah kesadaran atas kebutuhan kepada Allah semata dan hidup dalam kesadaran atas kecukupan pada makhluk.17 Yahya bin Mu'adz ketika ditanya tentang hakikat kefakiran ia menjawab bahwa seseorang tidak butuh lagi selain Allah, dan tanda kefakiran adalah tidak adanya harta benda. ${ }^{18}$

5. Sabar

Sabar secara bahasa adalah menahan atau bertahan, bertahan dan menahan diri dari rasa gelisah, cemas dan amarah, menahan lidah dari keluh kesah, menahan anggota tubuh dari

${ }^{15}$ HAMKA,Tasawuf Modern: Bahagia itu Dekat dengan Kita Ada di dalam Diri Kita, (Jakarta: Republika Penerbit, 2015), hlm. 263

${ }^{16}$ Abuddin Nata, Akhlak Tasawuf dan Karakter Mulia...,hlm. 173.

17Muhammad Fethullah Gulen, Tasawuf Untuk Kita Semua: Menapaki Bukit-bukit Zamrud Kalbu Melalui Istilah-istilah dalam Praktik Sufisme...,hlm. 297.

${ }^{18}$ Imam al-Qusyairy an-Naisabury, Risalah Qusyairyah: Induk Ilmu Tasawuf..., hlm. 335. 
kekacauan. ${ }^{19}$ Menurut Fethullah Gulen sabar adalah tabah menjalani penderitaan dan nestapa ketika menghadapi berbagai kejadian yang sulit untuk dihadapi dan sulit untuk dihindari. Abu Muhammad Ahmad alJurairy menjelaskan bahwa sabar adalah keadaan tidak membedakan keadaan bahagia atau menderita, disertai dengan ketentraman pikiran dalam keduanya. Bersikap sabar adalah mengalami kedamaian ketika menerima cobaan, meskipun dengan adanya kesadaran akan beban penderitaan." 20

6. Tawakkal

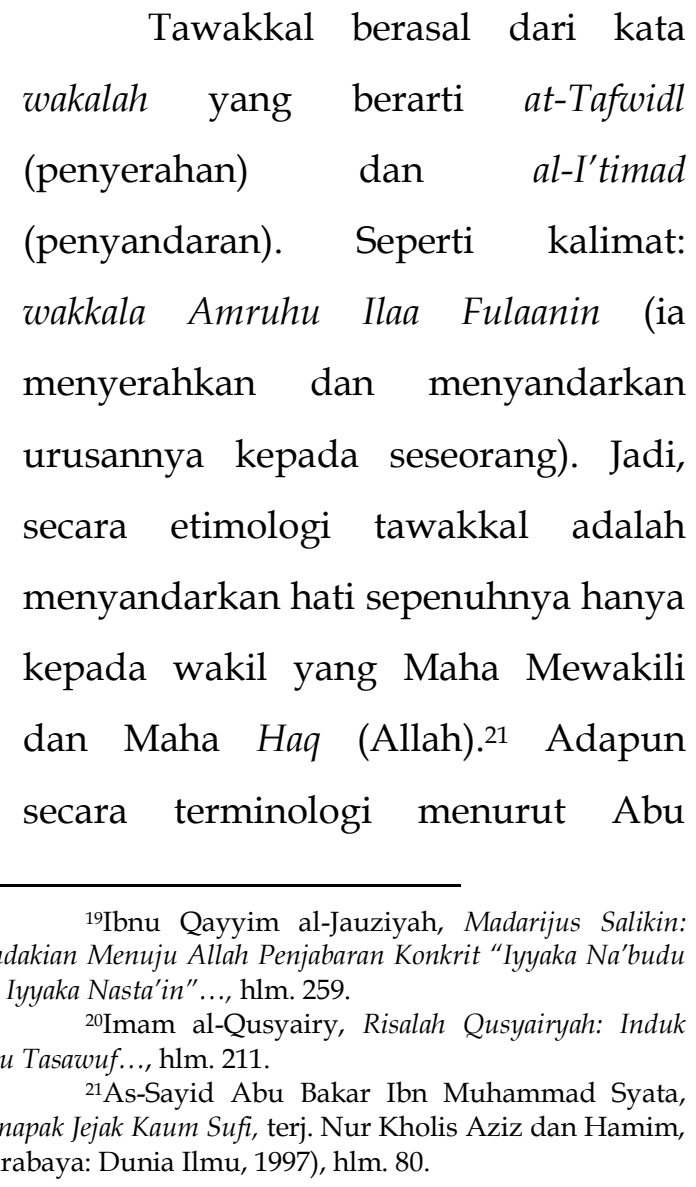

Tawakkal berasal dari kata (penyerahan) dan al-I'timad (penyandaran). Seperti kalimat: wakkala Amruhu Ilaa Fulaanin (ia darkan urusannya kepada seseorang). Jadi, menyandarkan hati sepenuhnya hanya dan Maha Haq (Allah). ${ }^{21}$ Adapun secara terminologi menurut Abu

\footnotetext{
Pendakian $M$ Wa Iyyaka Nasta'in"..., hlm. 259.

${ }^{20}$ Imam al-Qusyairy, Risalah Qusyairyah: Induk Ilmu Tasazuf..., hlm. 211.

Menapak Jejak Kaum Sufi, terj. Nur Kholis Aziz dan Hamim, (Surabaya: Dunia Ilmu, 1997), hlm. 80.
}

Turab an-Nakhsyabi seperti yang dikutib oleh Abu Nashr as-Sarraj berpendapat bahwa tawakkal adalah mengabdikan diri untuk beribadah, hati hanya terkait dengan Allah SWT. dan tenang dalam kecukupan. Jika diberi akan bersyukur, jika tidak diberi tetap bersabar dan rela dengan takdir yang telah ditentukan. ${ }^{22}$ Ketika Ibnu Atha' ditanya hakikat tawakkal, ia menjelaskan, "tawakkal adalah hendaknya hasrat yang mengebu-gebu terhadap perkara duniawi tidak muncul dalam dirimu, meskipun engkau sangat membutuhkannya, dan bahwa hendaknya engkau senantiasa bersikap qana'ah dengan Allah, meskipun engkau tergantung pada kebutuhan-kebutuhan duniawi itu."23

7. Ridha

Ridha artinya rela menerima apapun yang telah ditentukan dan ditakdirkan Tuhan kepadanya. Kerelaan mereka dalam menerima semata-mata karena Tuhan. Orang yang telah memiliki sifat "ridha" tidak akan mudah bimbang atau kecewa atas pengorbanan yang dialaminya, tidak merasa menyesal dalam hidup kekurangan, tidak iri hati atas

\footnotetext{
${ }^{22} \mathrm{Abu}$ Nashr as-Sarraj, Al-Luma': Rujukan Lengkap Ilmu Tasawuf..., hlm. 106.

${ }^{23}$ Imam al-Qusyairy an-Naisabury, Risalah Qusyairyah: Induk Ilmu Tasawuf..., hlm. 181.
} 
kelebihan-kelebihan yang telah didapat oleh orang lain, karena mereka kuat berpegang pada aqidah yang berkaitan dengan qadha dan qadhar yang semuanya itu dari Tuhan. ${ }^{24}$ Dalam literatur lain ridha adalah ketenangan hati dan ketentraman jiwa terhadap ketetapan dan takdir Allah SWT. serta kemampuan menyikapinya dengan tabah, termasuk terhadap derita, nestapa, dan kesulitan yang muncul darinya yang dirasakan oleh jiwa. ${ }^{25}$ Ibnu Ujaibah berkata bahwa ridha adalah menerima kehancuran dengan wajah tersenyum, atau bahagianya hati ketika ketetapan terjadi, atau tidak memilih-milih apa yang telah diatur dan ditetapkan oleh Allah, atau lapang dada dan tidak mengingkari apa-apa yang datang dari Allah." 26

\section{Ahwal Tasawuf}

Kata ahwal merupakan bentuk jamak dari haal artinya sesuatu dari kejernihan dzikir yang bertempat dalam hati, atau hati berada dalam kejernihan

${ }^{24}$ Mustafa Zahri, Kunci Memahami Ilmu Tasawuf, (Surabaya, PT Bina Ilmu, 1979), hlm. 71-72.

${ }^{25}$ Muhammas Fethullah Gulen,Tasawuf Untuk Kita Semua: Menapaki Bukit-bukit Zamrud Kalbu Melalui Istilah-istilah dalam Praktik Sufisme..., hlm. 197. hlm. 251-252 dzikir tersebut. ${ }^{27} \mathrm{Al}$-Haal (kondisi rohani), menurut banyak orang merupakan arti yang intuitif dalam hati, tanpa adanya unsur sengaja, usaha menarik dan usaha lainnya, dan rasa senang atau sedih, leluasa atau tergenggam, rindu atau berontak, rasa takut atau sukacita. Maka setiap al-haal merupakan karunia, dan setiap maqam adalah upaya. Pada al-haal datang dari Wujud itu sendiri, sedang almaqam diperoleh melalui upaya perjuangan. ${ }^{28}$ Baiknya amal merupakan hasil dari baiknya ahwal (keadaan spiritual). Sedangkan baiknya ahwal muncul setelah mengapai tahap kemampuan spiritual (maqam-maqam). ${ }^{29}$

Adapun ahwal tasawuf tersebut yaitu:

1. Muraqabah (Mawas Diri)

Menurut Imam al-Qusyairy anNaisabury secara bahasa muraqabah adalah mengamati tujuan. Sedangkan secara terminologi muraqabah yaitu keyakinan seorang sufi dengan kalbunya bahwasanya Allah SWT. melakukan pengamatan kepadanya dalam gerak dan diamnya sehingga membuat ia mengamati pekerjaan dan

\footnotetext{
${ }^{27} \mathrm{Abu}$ Nashr as-Sarraj, Al-Luma': Rujukan Lengkap Ilmu Tasawuf..., hlm. 88.

${ }^{28}$ Imam al-Qusyairy an-Naisabury, Risalah Qusyairyah: Induk Ilmu Tasawuf..., hlm. 24.

${ }^{29}$ Syaikh Ibn 'Atha'illah as-Sakandari, Kitab alHikam: Petuah-petuah Agung Sang Guru, terj. Ismail Ba'adillah, (Jakarta: Khatulistiwa Press, 2012), hlm. 58.
} 
hukum-hukum-Nya. ${ }^{30}$ Adapun

menurut Abu Nasrh as-Sarraj muraqabah adalah pengetahuan dan keyakinan seorang hamba, bahwa Allah SWT. selalu Melihat apa yang ada dalam hati dan nuraninya dan Maha Mengetahui. Maka dalam kondisi ini ia terus meneliti dan mengkoreksi bersitan-bersitan hati atau pikiran-pikiran tercela yang hanya akan menyibukkan hati sehingga lupa mengingat Tuhannya. ${ }^{31}$

2. Mahabbah (Cinta)

Sahl bin Abdullah tentang mahabbah berpendapat bahwa mahabbah adalah kecocokan hati dengan Allah SWT. dan senantiasa cocok dengan-Nya, serta SAW. dengan senantiasa mencintai yang sangat mendalam untuk selalu berdzikir (mengingat) Allah SWT. dan menemukan manisnya bermunajat kepada Allah SWT. ${ }^{32}$ Kondisi spiritual mahabbah bagi seorang hamba adalah melihat dengan kedua matanya terhadap nikmat yang Allah karuniakan kepadanya, dan dengan hati nuraninya ia melihat kedekatan Allah dengannya, segala

\footnotetext{
${ }^{30}$ Imam al-Qusyairy an-Naisabury, Risalah Qusyairyah: Induk Ilmu Tasawuf.., hlm. 218.

${ }^{31} \mathrm{Abu}$ Nashr as-Sarraj, Al-Luma': Rujukan Lengkap Ilmu Tasawuf..., hlm. 113.

${ }^{32} \mathrm{Abu}$ Nashr as-Sarraj, Al-Luma': Rujukan Lengkap Ilmu Tasawuf..., hlm. 119-120
}

perlindungan, penjagaan dan perhatian-Nya yang dilimpahkan kepadanya. ${ }^{33}$ Rabiah al Adawiyyah alBasriyyah (wafat $185 \mathrm{H} / 801 \mathrm{M}$ ) dianggap sebagai Sufi pertama yang menyatakan cintanya kepada Allah dan mengemukakan teori komprehensif tentang Cinta Ilahi. ${ }^{34}$ Cinta bagi Rabi'ah sukar didefinisikan, karena cinta berisi perasaan kerinduan kepada yang dicinta. Meski demikian, Rabi'ah telah membuat rumusan analisis melalui serangkaian katakatanya yang sangat terkenal, sebagai berikut:

Aku mencintai-Mu dengan dua cinta

Cinta karena diriku dan cinta karena

Diri-Mu

Cinta karena diriku

Adalah keadaanku yang senantiasa mengingat-Mu

Cinta karena Diri-Mu

Adalah Keadaan-Mu menyingkapkan tabir hingga Engkau kulihat Bagiku, tidak ada puji untuk ini dan itu.

Tapi sekalian puji hanya bagiMu selalu 35

\footnotetext{
${ }^{33} \mathrm{Abu}$ Nashr as-Sarraj, Al-Luma': Rujukan Lengkap Ilmu Tasawuf..., hlm. 119.

${ }^{34}$ Hassan Abu Hanieh, Sufism and Sufi Orders: God's Spiritual Paths: Adaptation and Renewalin the Context of Modernization,(Jordan: Friedrich-EbertStiftung, 2011), hlm. 70.

${ }^{35}$ Asfari dan Otto Sukatno, Mahabbah Cinta: Mengarungi Samudera Cinta Rabi'ah al-Adawiyah, (Yogyakarta: Pustaka Hati, 2018), hlm. 52.
} 
3. Khauf(Takut)

Khauf dalam tasawuf adalah hadirnya perasaan takut ke dalam diri seorang salik (orang yang menuju Tuhan) karena dihantui oleh perasaan dosa dan ancaman yang akan menimpanya. Seorang yang berada dalam khauf akan merasa lebih takut kepada dirinya sendiri, sebagaimana ketakutannya kepada musuhnya. Saat khauf menghampirinya, ia merasa tentram dan tenang karena kondisi hatinya semakin dekat dengan Tuhan. ${ }^{36}$ Al-Junaid pernah ditanya mengenai takut ia menjawab, "takut adalah datangnya deraan dalam setiap hembusan nafas." Dzun Nuun alMishri juga berkomentar tentang takut, "manusia akan tetap berada di jalan selama takut tidak tercabut dari kalbu, sebab jika telah hilang dari kalbu mereka, maka mereka akan tersesat." Adapun Hatim al-Asham juga menjelaskan, "setiap sesuatu ada perhiasannya dan perhiasan ibadah adalah takut. Tanda takut adalah membatasi keinginan."37 Dengan demikian, khauf adalah kondisi spiritual di mana seorang sufi takut

\footnotetext{
${ }^{36}$ Bachrun Rif'i dan Hasan Mud'is, Filsafat Tasawuf..., hlm. 224.

37Imam al-Qusyairy an-Naisabury, Risalah Qusyairyah: Induk Ilmu Tasawuf..., hlm. 126.
}

jika Allah tak meliriknya sehingga mendekat pada-Nya.

4. Raja' (harapan)

Raja' atau harapan adalah memerhatikan kebaikan dan berharap dapat mencapainya, melihat berbagai bentuk kelembutan dan nikmat Allah, dan memenuhi diri dengan harapan demi masa depan serta hidup demi meraih harapan tersebut. ${ }^{38}$ Dzun Nun al-Mishry saat menjelang ajalnya berkata: janganlah kalian memperdulikan aku, sebab aku telah terpersona oleh kelembutan Allah SWT. kepada diriku." Adapun Yahya

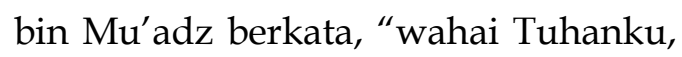
anugerahkanlah untukku yang termanis dalam hati berupa harapan kepada-Mu. Kata-kata paling sedap yang keluar dari lidahku berupa pujian kepada-Mu. Saat yang kuanggap paling berharga adalah saat aku akan berjumpa dengan-Mu. ${ }^{39}$

Raja' menuntut tiga perkara, yaitu (1) Cinta kepada apa yang diharapkannnya. (2) Takut harapannya itu hilang. (3) Berusaha untuk mencapainya. ${ }^{40}$ Raja' terbagi menjadi tiga tingkatan; pertama,

\footnotetext{
38Zaprulkhan, Ilmu Tasawuf: Sebuah Kajian Tematik..., hlm. 64 .

${ }^{39}$ Imam al-Qusyairy an-Naisabury, Risalah Qusyairyah: Induk Ilmu Tasawuf..., hlm. 135.

${ }^{40} \mathrm{M}$. Solihin, dan Rosihon Anwar, Ilmu Tasawuf..., hlm. 85
} 
berharap kepada Allah (fillah). Kedua, berharap keluasan rahmat Allah. Ketiga, berharap pahala Allah.

5. 'Uns (Suka Cita)

'Uns yaitu keadaan spiritual seorang sufi yang merasa intim tau akrab dengan Tuhannya, karena telah merasakan kedekatan dengan-Nya. ‘Uns adalah keadaan spiritual ketika qalbu dipenuhi rasa cinta, keindahan, kelembutan, belas kasih, dan pengampunan Allah.41 'Uns (bersuka cita) dengan Allah bagi seorang hamba adalah tingkatan paripurna kesuciannya dan kejernihan dzikirnya, sehingga ia merasa cemas dan gelisah dengan segala sesuatu yang melupakannya untuk mengingat Allah. Maka pada saat itulah ia sangat bersuka cita dengan Allah SWT.42 Seseorang yang berada pada kondisi spiritual 'Uns akan merasakan kebahagiaan, kesenangan, kegembiraan, serta sukacita yang meluap-luap. Kondisi spiritual seperti ini dialami oleh seorang sufi ketika merasakan kedekatan dengan Allah. Yang mana, hati dan perasaannya

\footnotetext{
${ }^{41 F a h r u d d i n, ~ " T a s a w u f ~ s e b a g a i ~ u p a y a ~}$ Membersikan Hati Guna Mencapai Kedekatan dengan Allah," Jurnal Pendidikan Agama Islam Ta'lim, Vol. 14, No. 1, 2016, hlm. 80, dalam https://jurnal.upi.edu/file/05, diakses pada hari Sabtu, 09 Maret 2019, jam 21.04 WIB.

${ }^{42} \mathrm{Abu}$ Nashr as-Sarraj, Al-Luma': Rujukan Lengkap Ilmu Tasawuf..., hlm. 135.
}

diliputi oleh cinta, kelembutan, keindahan, serta kasih sayang yang luar biasa, sehingga sangat sulit untuk dilukiskan. ${ }^{43}$ Dengan demikian 'Uns adalah kondisi spiritual di mana seorang sufi merasakan kesukacitaan hati atau kebahagiaan hati karena bisa akrab dengan Tuhan.

6. Yakin

Yakin dalam terminologi sufi yaitu sebuah kepercayaan yang kuat dan tak tergoyahkan tentang kebenaran pengetahuan yang dimiliki, karena penyaksiannya dengan segenap jiwanya dan dirasakan oleh seluruh ekspresinya, serta disaksikan oleh segenap eksistensinya..4 Adapun definisi lain dari yakin yaitu selamat dari keraguan dan syubhat, serta penguasaan atas pengetahuan yang akurat, tepat, dan benar, tanpa mengandung keraguan sama sekali.45 Menurut al-Junaid yakin merupakan kemantapan ilmu yang tidak dapat diubah dan tidak pula diganti serta tidak berubah apa yang ada di dalam hati. Yakin membuat seorang sufi siap

${ }^{43}$ Hasyim Muhammad, Dialog Antara Tasawuf dan Psikologi: Telaah atas Pemikiran Psikologi Humanistik Abraham Maslow, (Yogyakarta: Pustaka Pelajar, 2002), hlm. 53-54.

${ }^{44}$ Hasyim Muhammad, Dialog Antara Tasawuf dan Psikologi: Telaah atas Pemikiran Psikologi Humanistik Abraham Maslow, (Yogyakarta: Pustaka Pelajar, 2002), hlm. 57. 
mengemban beban dan mengahadapi bahaya serta mendorongnya untuk maju terus ke depan. Jika yakin tidak disertai ilmu, maka ia membawanya kepada kerusakan, sedangkan ilmu menyuruhnya untuk mundur ke belakang, dan jika ilmu tidak disertai yakin, maka pelakunya tidak mau bergerak dan tidak mau berusaha. ${ }^{46}$

Para sufi biasanya membahas yakin dalam tiga bagian:pertama, Ilm al-yaqin: yaitu pencapaian iman dan ketundukan terkuat yang berhubungan dengan hal-hal yang ingin dicapai dengan memperhatikan dalil-dalil dan petunjuk yang jelas.Kedua, 'Ain al-yaqin: yaitu pencapaian makrifat melampaui batasan definisi yang dilakukan oleh ruh melalui penyingkapan, musyahadah, persepsi dan kesadaran.Ketiga, Haqq al-yaqin: yaitu anugerah berupa kebersamaan (ma'iyyah) yang mengandung banyak rahasia, tanpa tirai dan penghalang, yang melampaui imajinasi manusia serta tanpa kammiyyah ataupun kaifiyyah. Sebagian sufi menafsirkan yang satu ini sebagai fana' sang hamba

\footnotetext{
${ }^{45}$ Muhammad Fethullah Gulen, Tasawuf Untuk Kita Semua: Menapaki Bukit-bukit Zamrud Kalbu Melalui Istilah-istilah dalam Praktik Sufisme...,hlm. 225.

${ }^{46}$ Ibnu Qayyim, Madarijus Salikin: Pendakian Menuju Allah Penjabaran Konkrit "Iyyaka Na'budu Wa Iyyaka Nasta'in..., hlm. 352-353.
}

pada seluruh jati diri, ego, diri, dan kebersamaannya dengan Allah al-Haqq SWT. ${ }^{47}$

\section{Relevansi Tasawuf dengan Zaman Sekarang}

Setiap orang yang beragama Islam tentunya ingin dekat dengan Tuhannya Allah SWT. Ada begitu banyak jalan untuk bisa dekat dengan Allah SWT, salah satunya adalah dengan jalan tasawuf. J. Spencer Trimingham penulis buku The Sufi Orders in Islam berpendapat bahwa setiap orang mungkin baginya untuk memiliki pengalaman langsung dengan Tuhan jikalau ia mau untuk menempatkan dirinya untuk mempraktekan ajaran tasawuf.48 Ini artinya siapa saja bisa memiliki pengalaman dengan Tuhan, tanpa terkecuali. Dalam jurnal yang ditulis oleh Arif Zamhari mengatakan bahwa tradisi sufi telah tumbuh secara signifikan di dunia Muslim modern, termasuk Indonesia. Saat ini, sufisme tidak hanya dipraktikkan oleh penduduk desa, petani,dan orang-orang yang tidak berpendidikan, tetapi juga dipraktekkan oleh kaum urban, elit nasional, dan orangorang berpendidikan. Apalagi, sudah

\footnotetext{
47Muhammad Fethullah Gulen, Tasawuf Untuk Kita Semua: Menapaki Bukit-bukit Zamrud Kalbu Melalui Istilah-istilah dalam Praktik Sufisme..., hlm. 229.

48J. Spencer Trimingham, The Sufi Orders in Islam, (London: Oxford University Press, 1971), hlm. 1.
} 
mengalami inovasi yang signifikan dalam hal prakteknya dan organisasi. ${ }^{49}$

Pentingnya ajaran tasawuf dalam kehidupan sehari-hari karena tidak lepas dari adanya dua unsur yang saling melengkapi, yaitu unsur lahir dan unsur batin. Unsur lahir diwakili oleh syari'ah, sementara unsur batin diwakili oleh haqiqah. Syari'ah merupakan pintu masuk untuk menuju haqiqah, dan haqiqah merupakan tujuan dari pelaksanaan syri'ah.50 Perbedaan antara syari'ah dan haqiqah dapat diibaratkan seperti kulit dan isi atau lingkaran dan titik tengahnya. Rene Guenon, seorang tokoh ternama dalam mistisisme Kristen yang kemudian masuk Islam melalui pendekatan sufisme, dia mengatkan bahwa antara syari'ah dan haqiqah tidak dapat dipisahkan. Demikian pula dengan Abu A'li al-Daqqaq juga mengatakan bahwa antara syari'ah dan haqiqah tidak dapat dipisahkan dalam Islam. Ia menggambarkan dengan ayat, bahwa ayat "iyyaka na'bud" sebagai ayat yang berkonotasi syari'ah, sementara "iyyaka nasta'in" sebagai ayat yang berkonotasi haqiqah.

${ }^{49}$ Arif Zamhari, “Socio-Structural Innovations In Indonesia's Urban Sufism The Case Study Of The Majelis Dzikir And Shalawat Nurul Mustafa," Journal Of Indonesian Islam, Volume 07, Number 01, June 2013, hlm. 119, dalam http://jiis.uinsby.ac.id/index.php/JIIs/article/view/122, diakses pada hari Sabtu, 09 Maret, 2019, jam 20.35 WIB. ${ }^{50}$ Hasan Mu'is, Filsafat Tasawuf, (Bandung: Pustaka Setia, 2010), Hlm.56.
Melihat kepada maqamatmaqamat tasawuf dinilai relevan dengan perkembangan zaman. Mulai dari taubat, wara', zuhud, fakir, sabar, tawakkal dan ridha. taubat dalam tasawuf yang menghendaki manusia agar senantiasa memperbaiki diri dari kekhilafankekhilafan yang terjadi senantiasa istighfar dan muhasabbah diri. Dalam kajian sufistik, ada tiga syarat taubat yang harus dipenuhi: pertama, dia harus mengehentikan maksiatnya. Kedua, dia harus menyesali perbuatan yang terlanjur dilakukannya. Ketiga, dia harus berniat dengan sungguh-sungguh untuk tidak mengulangi perbuatan itu kembali. ${ }^{51}$ Titik puncak atau klimak dari bertaubat adalah awbah, setelah melalui fase taubah dan inabah. Taubah adalah taubat karena takut akan siksa Allah. Inabah adalah taubat karena mengharap pahala Allah. Sedangkan awbah adalah bertaubat karena Allah, tak berharap mendapat surga atau dijauhkan dari neraka. ${ }^{52}$ Dengan demikian maqamat taubat merupakan jenjang pertama untuk menuju kedekatan hakiki dengan Tuhan. Pada tahap ini seorang sufi dikehendaki untuk membersihkan dirinya dari prilaku yang menimbulkan dosa dan rasa bersalah.

${ }^{51}$ Syaikh Abdul Qadir Isa, Hakekat Tasawuf, (Jakarta: Qisthi Press, 2005), hlm. 195. 
Begitu halnya dengan wara', melihat perkembangan zaman yang semakin hari semakin banyak ditemukan hal-hal yang kejelasannya diragukan, maka adanya wara' hendaknya menjadikan sufi khususnya dan manusia umumnya untuk waspada dan berhatihati bahkan meninggalkan perkaraperkara syubhat. Sikap menjauhi diri dari yang syubhat ini sejalan dengan hadits Nabi yang artinya: "Barangsiapa yang dirinya terbebas dari syubhat, maka sesungguhnya ia telah terbebas dari yang haram." (H.R. Bukhari). Hadits tersebut menunjukkan bahwa syubhat lebih dekat pada yang haram. Kaum sufi menyadari benar bahwa setiap makanan, minuman, pakaian, dan sebagainya yang haram dapat memberi pengaruh bagi orang yang memakan, meminum dan memakannya. Orang yang demikian akan keras hatinya, sulit mendapatkan hidayah dan ilham dari Tuhan. Hal ini dipahami dari hadits Nabi yang menyatakan bahwa setiap makanan yang haram yang dimakan oleh manusia akan menyebabkan noda hitam pada hati yang lama-kelamaan hati menjadi keras. Hal ini sangat ditakuti oleh para sufi yang senantiasa mengharapkan Nur Illahi yang

52Owobo, 50 Komik Sufi: Cara Asyik Menyimak Kisah Hikmah, dan Ajaran Tasawuf, (Jakarta: Zaman, 2014), hlm. 46 . dipancarkan lewat hatinya yang bersih. ${ }^{53}$ Dari penjelasan di atas dapat dipahami bahwa maqamat wara' adalah kedudukan spiritual hamba yang menjauhkan diri dari hal-hal syubhat dan tidak berfaedah demi mendapatkan kedekatan dengan Tuhan.

Demikian dengan zuhud, zuhud zaman modern adalah zuhud semangat berjuang, yang menghendaki manusia agar bisa mengapai dunia, namun hal itu sama sekali tak melalaikan kedekatannya dengan Tuhan. Menurut Ibnu 'Athaillah al-Sakandariada dua tanda seseorang yang zuhud terhadap dunia, yaitu tanda ketika memiliki harta dan tanda ketika tidak memilikinya. Ketika memiliki harta, seorang zahid selalu mendahulukan orang lain, dan ketika tidak tidak memilikinya, ia selalu bersikap lapang dan menerima. Orang yang mendahulukan kepentingan orang lain berarti mensyukuri nikmat keberadaan, dan orang yang merasa lapang ketika tidak punya berarti mensyukuri nikmat ketiadaan. Itulah buah pemahaman dan makrifat. Sebab, anugerah Allah tidak hanya berupa pemberian harta, Dia tidak memberipun merupakan salah satu bentuk anugerahNya. Bahkan, ketika tidak memberi,

${ }^{53}$ Abuddin Nata, Akhlak Tasawuf dan Karakter Mulia...,hlm. 172-173. 
nikmat-Nya menjadi lebih sempurna.54 Maqamat zuhud ini bisa dikatakan sebagai kedudukan spiritual yang menghendaki agar seorang sufi meraih kedekatan kepada Allah dengan jalan hidup di dunia tanpa ternodai dan terpengaruh sedikitpun.

Fakir dalam tasawuf bukan berarti fakir harta atau tidak butuh pada harta, melainkan fakir yang dimaksud adalah butuh akan Allah, sehingga selalu mengantungkan segala kehidupan pada Allah. Ibrahim bin Ahmad al-Khawwash berkata: "kefakiran itu selendang kemuliaan, pakaian para rasul, jubbah orang-orang sholeh, mahkota orang-orang yang bertakwa, perhiasan orang-orang mukmin, harta jarahan perang orangorang arif, harapan para murid, bentengbenteng orang yang taat, penjara orangorang yang berdosa, penghapus kejelekan, pelipatganda kebaikan, pengangkat kuasa, kemuliaan (karamah) bagi orang-orang baik yang menjadi Wali-Nya. Kefakiran adalah simbol orang-orang saleh dan kebiasaan orang-orang yang bertaqwa. ${ }^{55}$ Menurut Abu Nasrh as-Sarraj maqamat fakir memiliki tiga tingkatan: pertama, orang yang tidak memiliki apa-apa dan

\footnotetext{
${ }^{54}$ Ibnu 'Athaillah al-Sakandari, Terapi Makrifat Misteri Berserah Kepada Allah, (Jakarta: Zaman, 2011), hlm. 143.

${ }^{55} \mathrm{Abu}$ Nashr as-Sarraj, Al-Luma': Rujukan Lengkap Ilmu Tasawuf, terj. Wasmukan dan Samson Rahman, (Surabaya: Risalah Gusti, 2002), hlm. 98-99.
}

tidak meminta apapun kepada seseorang, baik secara lahir maupun batin. Kedua, orang yang tidak memiliki apapun. Namun ia tidak meminta kepada siapapun, tidak mencari dan juga tidak memberi isyarat atas kefakirannya. Ketiga, tidak memiliki apa-apa. Jika ia membutuhkan sesuatu ia akan mengungkapkannya kepada sebagian temannya yang ia kenal, yang mana bila ia mengungkapkan kepadanya ia akan merasa senang. ${ }^{56}$ Dari penjelasan di atas dapat dipahami bahwa maqamat tasawuf adalah sebuah kedudukan spiritual penghambaan seorang sufi bahwa yang dibutuhkannya hanyalah Allah semata.

Dalam menjalani kehidupan begitu akan banyak hal suka dan duka yang kita temukan sabar sangat diperlukan sepanjang manusia hidup maka akan selalu ada cobaan menghampirinya maka selama itu pula maka sabar akan selalu relevan dengan kehidupan manusia, sebagai benteng pertahanan dalam menjalani ketaatan pada Allah, menghindari kedurhakaan dan bertahan dari segala macam cobaan. Untuk mengklasifikasikan makna dan derajat kesabaran maka sabar dibagi menjadi tiga tingkat yaitu: pertama, sabar dalam menghindari kedurhakaan dengan

${ }^{56} \mathrm{Abu}$ Nashr as-Sarraj, Al-Luma': Rujukan Lengkap Ilmu Tasawuf..., hlm. 99-100. 
memerhatikan peringatan, tetap teguh keimanan dan waspada hal yang haram dan menghindari kedurhakaan karena malu.Kedua, sabar dalam ketaatan dengan menjaga ketaatan itu secara terusmenerus, memeliharanya dengan keikhlasan dan berdasarkan ilmu. Ketiga, sabar dalam musibah dengan memerhatikan pahala yang baik, menunggu rahmat datang, menganggap musibah sebagai hal kecil dan menghitung nikmat-nikmat masa lampau. ${ }^{57}$

Hidup tidak cukup dengan Do,a saja tawakkal menjadi bagian dari tercapainya apa yang kita minta kepada Allah. Tawakkal dalam tasawuf merupakan semangat juang dalam kehidupan manusia, agar senantiasa berusaha dulu, setelah itu serahkan hasilnya kepada Allah, hal ini tentunya sesuai dengan karekteristik masyarakat modern yang cenderung giat bekerja, namun mengantungkan hasilnya kepada Allah SWT. Al-Ghazali dan Ibnu Ujaibah membagi tawakal ke dalam tiga tingkatan: pertama, tingkatan yang paling rendah, yaitu engkau bersama Allah, sebagaimana halnya muwakkil (orang yang mewakilkan) bersama wakilnya yang baik dan ramah. Kedua, tingkatan pertengahan, yaitu engkau bersama Allah, sebagaimana

${ }^{57}$ Bachrun Rif'i dan Hasan Mud'is, Filsafat Tasawuf.., hlm. 213. halnya seorang anak bersama ibunya. Seorang anak tidak akan mencurahkan segala urusannya kecuali kepada ibunya. Ketiga, tingkatan yang paling tinggi, yaitu engkau bersama Allah, sebagaimana halnya orang yang sakit di hadapan dokternya. ${ }^{58}$ Adapun perbedaan antara tingkatan-tingkatan ini adalah bahwa pada tingkatan pertama, kadang-kadang dalam pikirannya terdetik sebuah kecurigaan. Pada tingkatan kedua, tidak ada kecurigaan, akan tetapi dia akan selalu bergantung pada ibunya ketika dia sedang membutuhkan sesuatu. Adapun pada tingkatan ketiga, tidak ada kecurigaan dan ketergantungan pada yang lain, karena dirinya telah fana dan setiap waktu dia melihat apa yang dilakukan Allah terhadapnya.59 Dengan demikian dapat dipahami bahwa maqamat tawakkal adalah kedudukan spiritual seorang sufi yang menghendaki adanya ketergantungan dan mewakilkan segala urusan hanya pada Allah semata.

Tujuan dalam hidup ini salah satunya mendapatkan ridha Allah. Penting untuk memiliki sifat ridha kiranya, dikarenakan lika-liku kehidupan yang jika tidak ada keridhaan di dalamnya maka yang akan muncul adalah

\footnotetext{
hlm. 265

58Syaikh Abdul Qadir Isa, Hakekat Tasawuf..., 59Syaikh Abdul Qadir Isa, Hakekat Tasawuf..., hlm. 266.
} 
rasa berkeluh kesah, msyarakat modern yang saat ini berpatokan pada kemampuan akalnya jika tidak memiliki keridahan dalam hidup maka gejala stress akan menghampiri dirinya. Dzun Nun alMishri menyatakan, "tanda-tanda ridha ada tiga: (1) tindakan sang hamba meninggalkan keinginannya karena mengutamakan keinginan Allah SWT. sebelum ia melakukan sesuatu. (2) Pengetahuan sang hamba bahwa yang terbaik adalah yang dipilih oleh Allah setelah ia melakukan sesuatu. (3) Tidak gelisah serta tetap mencintai Allah ketika sang hamba berada di tengah musibah.60 Buah dari ridha adalah munculnya kesenangan dan ketenangan menakjubkan yang berembus dari keridhaan Allah SWT. yang berpadu secara langsung dengan besarnya cita-cita dan harapan yang dimiliki seorang hamba.61 Dari paparan di atas dapat disimpulkan bahwa maqamat ridha adalah kedudukan spiritual di mana seorang sufi hanya melihat kebahagiaan segala apa yang terjadi padanya karena adanya rasa rela pada dirinya.

Adapun ahwal tasawuf atau kondisi spiritual yang dirasakan oleh

\footnotetext{
${ }^{60}$ Muhammad Fethullah Gulen, Tasawuf Untuk Kita Semua: Menapaki Bukit-bukit Zamrud Kalbu Melalui Istilah-istilah dalam Praktik Sufisme..., hlm. 202.

${ }^{61}$ Muhammad Fethullah Gulen, Tasawuf Untuk Kita Semua: Menapaki Bukit-bukit Zamrud Kalbu Melalui Istilah-istilah dalam Praktik Sufisme..., hlm. 201.
}

seorang sufi dalam perjalanannya mendekat pada Allah, tentu adalah sebuah kondisi spiritual yang diimpiimpikan oleh seorang sufi untuk bisa merasakannya. Hal sebagai sebuah kondisi yang singgah dalam kalbu, merupakan efek dari peningkatan maqamat seseorang. Secara teoritis, memang bisa dipahami bahwa kapanpun seorang hamba mendekat kepada Allah dengan cara berbuat kebajikan, ibadah, riyadhah, dan mujahadah, maka Allah akan memanifestasikan diri-Nya dalam kalbu hamba tersebut. ${ }^{62}$ Kondisi seperti ini tentu akan tetap relevan dengan kehidupan manusia selama manusia masih beragama, pengalaman dengan Tuhan tentu adalah hal yang diinginkan, apalagi itu adalah sebuah pemberian atau anugerah dari Tuhan.

Sedangkan hal kata jamak dari ahwal artinya suasana atau keadaan yang menyelimuti kalbu, yang diciptakan sebagai hak prerogatif Allah dalam hati setiap hambanya, tidak ada sufi yang mampu merubah keadaan tersebut apabila dating saatnya, atau memperhatikannya apabila pergi.63 Intinya adalah diperkenalkan dengan maksud sebagai bagian pentinnya tasawuf

\footnotetext{
${ }^{62}$ Media Zainul Bahri, Tasawuf Mendamaikan Dunia...,hlm. 90.

${ }^{63}$ Abuddin Nata, Akhlak Tasawuf, (Jakarta: Rajawali Pers, 2002), hlm. 177.
} 
yang tujuannya perjalanan spiritual baik itu pemahaman tentang Allah, keridhaanya, cintanya.

\section{Kesimpulan}

Maqamat dan ahwal adalah dua hal yang berbeda namun memiliki hubungan.

Dikatakan berbeda karena maqamat adalah kedudukan spiritual seorang hamba yang diupayakan dengan sungguh-sungguh dan komitmen yang kuat serta istiqamah sehingga mencapai puncak dari maqamat tersebut. Adapun ahwal adalah kondisi spiritual seorang sufi yang memiliki pengalaman dengan Tuhan yang ia tidak diusahakan namun merupakan sebuah pemberian dari Tuhan. Maqamat dan ahwal adalah konsep subjektif yang masing-masing sufi memiliki pandangannya tersendiri dan jumlah kuantitasnya. Dalam paper ini maqamat dan ahwal yang ditampilkan adalah menurut Abu Nashr as-Sarraj pengarang kitab Al-Luma': Rujukan Lengkap Ilmu Tasawuf, yang mana maqamat itu ada 7 yaitu: taubat, wara, zuhud, fakir, sabar, tawakal, dan ridha. Adapun ahwal adalah muraqabah, mahabbah, khauf, raja', syauq, 'uns, tuma'ninah, musyahadah, dan yakin. Adapun relevansi konsep-konsep tasawuf dengan kehidupan sekarang adalah bahwasanya konsep-konsep tersebut akan menjadi suatu pedoman untuk mencapai kedekatan yang hakiki dengan Tuhan, dan bisa menjadi acuan untuk meneliti lebih mendalam lagi mengenai tasawuf.

\section{Referensi}

1. Al-Sakandari, Ibnu 'Athaillah.2011. Terapi Makrifat Misteri Berserah Kepada Allah. Jakarta: Zaman

2. -----. 2012.Kitab al-Hikam: Petuahpetuah Agung Sang Guru, terj. Ismail Ba'adillah. Jakarta: Khatulistiwa Press.

3. Al-Yamani, Syekh Yahya ibn Hamzah.2012. Pelatihan Lengkap Takiyatun Nafs: Memandu Anda Membersihkan Hati dan Menumbuhkan Jiwa Mulia Agar Hidup Lebih Berhasil dan Lebih Bahagia.Terj. Maman Abdurrahman Assegaf. Jakarta: Zaman.

4. Al-Jauziyah, Ibnu Qayyim.2017. Madarijus Salikin: Pendakian Menuju Allah Penjabaran Konkrit "Iyyaka Na'budu Wa Iyyaka Nasta'in." Terj. Kathur Suhardi. Jakarta: Pustaka alKautsar.

5. An-Naisabury, Imam al-Qusyairy. 2014. Risalah Qusyairyah: Induk Ilmu Tasawuf. Terj. Mohammad Luqman Hakiem. Surabaya: Risalah Gusti.

6. ------. 2007.Risalah Qusyairiyah: Sumber Kajian Ilmu Tasazuf, terj. Umar Faruq. Jakarta: Pustaka Amani.

7. As-Sarraj, Abu Nashr as-Sarraj. 2002. Al-Luma': Rujukan Lengkap Ilmu Tasawuf. Terj. Wasmukan dan Samson Rahman. Surabaya: Risalah Gusti.

8. Asfari, dan Otto Sukatno. 2018. Mahabbah Cinta: Mengarungi Samudera Cinta Rabi'ah al-Adawiyah. Yogyakarta: Pustaka Hati.

9. Bahri, Media Zainul. 2010. Tasawuf Mendamaikan Dunia. Jakarta: Gapprint. 
10. Fahruddin. 2016. “Tasawuf sebagai upaya Membersikan Hati Guna Mencapai Kedekatan dengan Allah." Jurnal Pendidikan Agama Islam Ta'lim.Vol. 14. No. 1. Dalam https://jurnal.upi.edu/file/05.

11. Gulen, Muhammad Fethullah. 2013.Tasawuf Untuk Kita Semua: Menapaki Bukit-bukit Zamrud Kalbu Melalui Istilah-istilah dalam Praktik Sufisme. Terj. Fuad Syaifudin Nur. Jakarta: Republika.

12. HAMKA. 2015.Tasawuf Modern: Bahagia itu Dekat dengan Kita Ada di dalam Diri Kita. Jakarta: Republika Penerbit.

13. Hanieh, Hassan Abu. 2011.Sufism and Sufi Orders: God's Spiritual Paths: Adaptation and Renewalin the Context of Modernization. Jordan: Friedrich-EbertStiftung.

14. Isa, Syaikh Abdul Qadir. 2005.Hakekat Tasawuf. Jakarta: Qisthi Press, 2005.

15. Muhammad, Hasyim.2002. Dialog Antara Tasawuf dan Psikologi: Telaah atas Pemikiran Psikologi Humanistik Abraham Maslow. Yogyakarta: Pustaka Pelajar.

16. Nata, Abuddin. 2013.Akhlak Tasawuf dan Karakter Mulia, (Jakarta: Rajawali Pers.

17. Nata, Abuddin. 2002. Akhlak Tasawuf, (Jakarta: Rajawali Pers.

18. Owobo. 2014. 50 Komik Sufi: Cara Asyik Menyimak Kisah Hikmah, dan Ajaran Tasawuf. Jakarta: Zaman.

19. Rif'I, Bachrun, dan Hasan Mud'is. 2010. Filsafat Tasawuf. Bandung: CV. Pustaka Setia.

20. Solihin, M,dan Rosihon Anwar. 2008. Ilmu Tasawuf. Bandung: CV Pustaka Setia.

21. Syata, As-Sayid Abu Bakar Ibn Muhammad. 1997. Menapak Jejak Kaum Sufi. Terj. Nur Kholis Aziz dan Hamim. Surabaya: Dunia Ilmu.

22. Schimmel, Annemarie. 1975.Mystical Dimensions of Islam. America: The University of North Carolina Press.
23. Tohir, Moenir Nahrowi. 2012. Menjelajahi Eksistensi Tasawuf: Meniti Jalan Menuju Tuhan. Jakarta: PT asSalam Sejahtera.

24. Trimingham, J. Spencer.1971. The Sufi Orders in Islam. London: Oxford University Press.

25. Yunus, Mahmud. 1990.Kamus Arab. Jakarta:Hidakarya Agung.

26. Zahri, Mustafa. 1979.Kunci Memahami Ilmu Tasawuf. Surabaya, PT Bina Ilmu.

27. Zamhari, Arif. 2013. "Socio-Structural Innovations in Indonesia's Urban Sufism The Case Study of The Majelis Dzikir and Shalawat Nurul Mustafa." Journal Of Indonesian Islam. Volume 07. Number $01 . \quad J u n e . \quad$ Dalam http://jiis.uinsby.ac.id/index.php/JII s/article/view/122.

28. Zaprulkhan. 2016. Ilmu Tasawuf: Sebuah Kajian Tematik. Jakarta: Rajawali Pers. 